\title{
Logros y desafíos en el control de zoonosis en Chile
}

\author{
Alonso Parra Garcés \\ MV. Oficina de zoonosis, Ministerio de salud de Chile. Email: alonso.parra@minsal.cl
}

\begin{abstract}
Resumen
La Oficina de Zoonosis y Vectores es el organismo técnico del Ministerio de Salud responsable de diseñar políticas, normativas, planes y programas con la finalidad de disminuir la morbimortalidad e impacto de las zoonosis y enfermedades vectoriales en el país.
\end{abstract}

La ejecución sistemática y sostenida de acciones de prevención y control, ha permitido alcanzar importantes logros, entre los que cabe destacar:

- $\quad$ Eliminación de la Rabia transmitida por el perro (variantes V1 y V2 del virus rábico)

- Interrupción de la transmisión vectorial de la enfermedad de Chagas

- $\quad$ Mantención de la eliminación de malaria y dengue (territorio continental)

- Iniciativas focalizadas de prevención y control de hidatidosis

- Generación de capacidades para la investigación y respuesta ante brotes y casos de zoonosis endémicas y emergentes

Mantener estos logros y asumir los desafíos asociados a las zoonosis endémicas y a la emergencia y remergencia de enfermedades, obliga a la implementación de una gestión integrada de prevención y control, que consiste en el desarrollo de acciones coordinadas entre los distintos ámbitos de la prevención y control, incluyendo la asistencia al paciente, la promoción de la salud y la participación comunitaria.

Por otra parte, es fundamental la coordinación efectiva con el sector Agricultura para la implementación del enfoque "Una Salud" en el enfrentamiento de problemas de interés común. Así mismo, es necesario fortalecer la coordinación con universidades y sociedades científicas para la generación de evidencia que permita respaldar los planes y programas, así como la formación, capacitación y perfeccionamiento profesional. 